Prepared in cooperation with Fugro Airborne Surveys, Limited, and the U.S. Army Cold Regions Research and Engineering Laboratory

\title{
Airborne Electromagnetic and Magnetic Geophysical Survey Data of the Yukon Flats and Fort Wainwright Areas, Central Alaska, June 2010
}

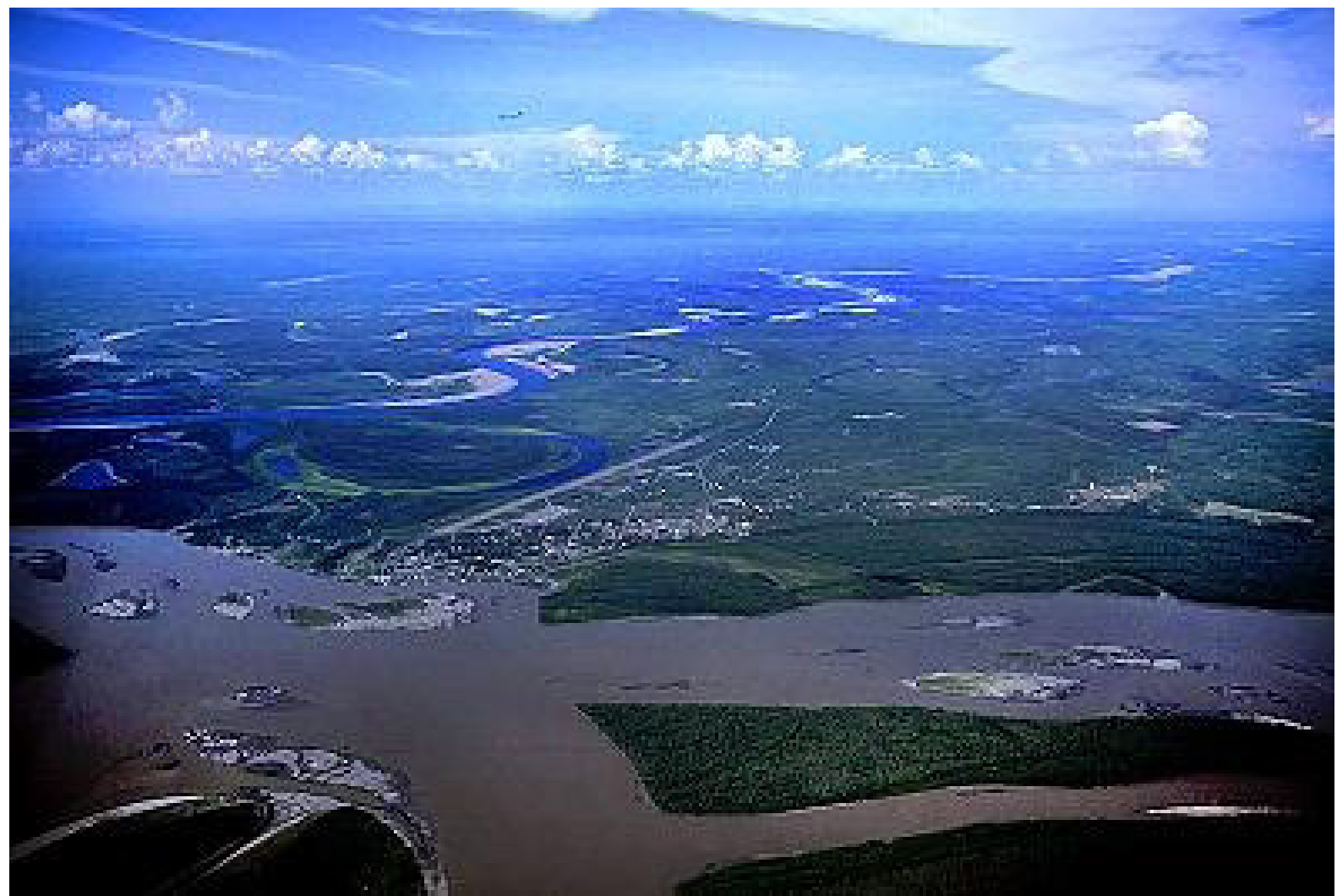

Open-File Report 2011-1304

U.S. Department of the Interior

U.S. Geological Survey 


\section{Airborne Electromagnetic and Magnetic Geophysical Survey Data of the Yukon Flats and Fort Wainwright Areas, Central Alaska, June 2010}

By Lyndsay B. Ball, Bruce D. Smith, Burke J. Minsley, Jared D. Abraham, Clifford I. Voss, Beth N. Astley, Maria Deszcz-Pan, and James C. Cannia

Prepared in cooperation with Fugro Airborne Surveys, Limited, and the U.S. Army Cold Regions Research and Engineering Laboratory

Open-File Report 2011-1304 


\title{
U.S. Department of the Interior \\ KEN SALAZAR, Secretary
}

\section{U.S. Geological Survey \\ Marcia K. McNutt, Director}

\section{U.S. Geological Survey, Reston, Virginia 2011}

\author{
For product and ordering information: \\ World Wide Web: http://www.usgs.gov/pubprod \\ Telephone: 1-888-ASK-USGS
}
For more information on the USGS-the Federal source for science about the Earth, its natural and living resources, natural hazards, and the environment:
World Wide Web: http://www.usgs.gov
Telephone: 1-888-ASK-USGS Any use of trade, product, or firm names is for descriptive purposes only and does not imply
endorsement by the U.S. Government.

Although this report is in the public domain, permission must be secured from the individual copyright owners to reproduce any copyrighted material contained within this report.

\section{Suggested citation:}

Ball, L.B., Smith, B.D., Minsley, B.J., Abraham, J.D., Voss, C.I., Astley, B.N., Deszcz-Pan, Maria, and Cannia, J.C., 2011, Airborne electromagnetic and magnetic geophysical survey data of the Yukon Flats and Fort Wainwright areas, central Alaska, June 2010: U.S. Geological Survey Open-File Report 2011-1304, 21 p. 


\section{Contents}

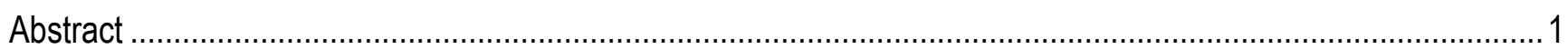

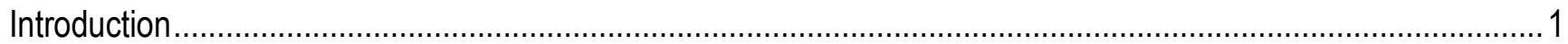

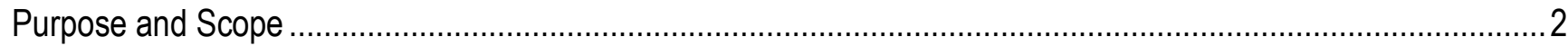

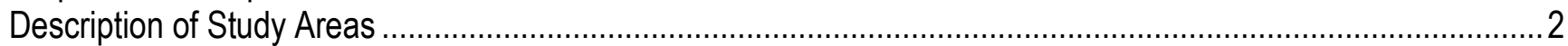

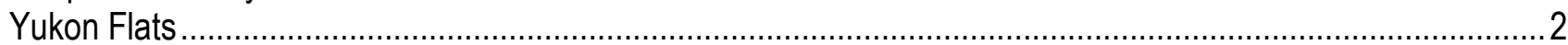

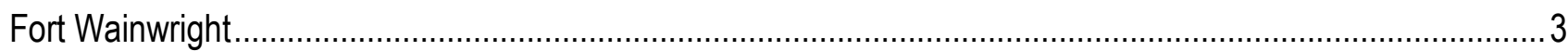

Airborne Electromagnetic and Magnetic Survey: Methods and Measurements...................................................

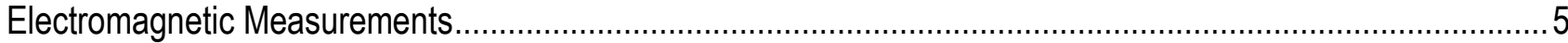

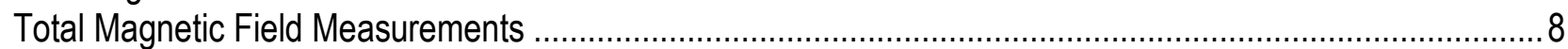

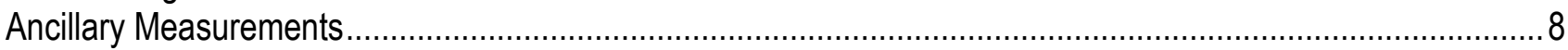

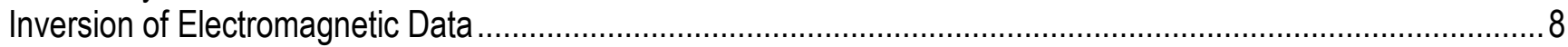

Model Assessment Using the Depth of Investigation (DOI) Metric …….......................................................... 11

Deriving Calibration Factors for the Airborne Electromagnetic Data ............................................................ 11

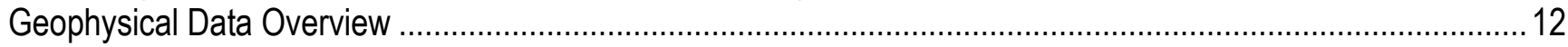

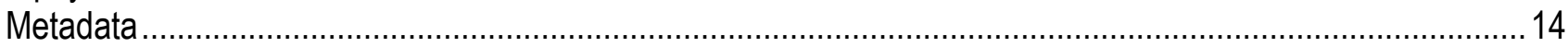

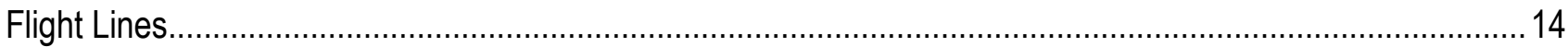

Line Data

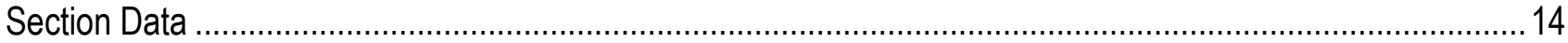

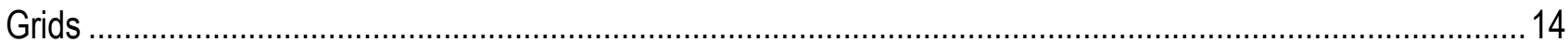

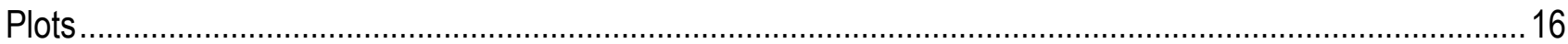

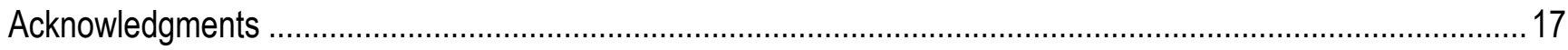

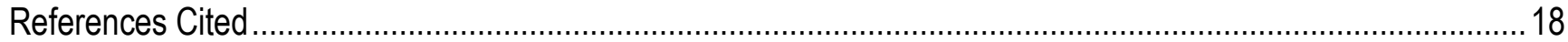

Appendix 1: Fugro Airborne, Ltd., Geophysical Report............................................................................ link

Appendix 2: Calibration Procedure Summary .......................................................................................

Appendix 3: Fort Wainwright Poster Presentation....................................................................................ink

\section{Figures}

1. Site maps showing (A) the Yukon Flats and (B) Fort Wainwright study areas with respect to the Yukon River and its major tributaries.

2. Helicopter-borne RESOLVE Geophysical system similar to that used during this study ....

3. Depth of penetration or imaging as a function of frequency and Earth resistivity for the RESOLVE

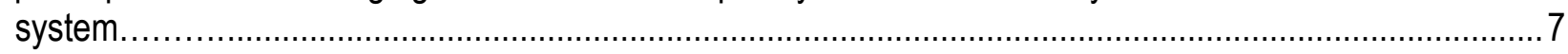

4. Screen shot of the ESRI application ArcMap being used to display Geosoft grids.................................... 16

\section{Tables}

1. Flight-line direction and spacing for each survey area..........................................................................

2. Frequencies and measurement sensitivities for the airborne electromagnetic survey .....................................

3. Layer thicknesses used for airborne electromagnetic inversions.................................................................... 10

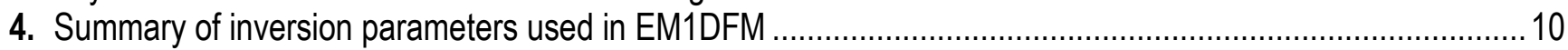

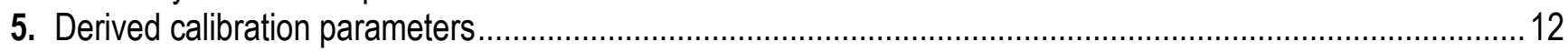

6. Digital data organization and description for files and folders for the Yukon Flats study area ........................13

7. Digital data organization and description for files and folders for the Fort Wainwright study area ....................13 


\section{Conversion Factors}

SI to Inch/Pound

\begin{tabular}{ccc}
\hline Multiply & By & To obtain \\
\hline meter $(\mathrm{m})$ & 3.281 & foot $(\mathrm{ft})$ \\
kilometer $(\mathrm{km})$ & 0.6214 & mile $(\mathrm{mi})$ \\
square meter $\left(\mathrm{m}^{2}\right)$ & 0.0002471 & acre \\
square kilometer $\left(\mathrm{km}^{2}\right)$ & 247.1 & acre \\
nanotesla $(\mathrm{nT})$ & 1 & gamma \\
\hline
\end{tabular}

Temperature in degrees Celsius $\left({ }^{\circ} \mathrm{C}\right)$ may be converted to degrees Fahrenheit $\left({ }^{\circ} \mathrm{F}\right)$ as follows: ${ }^{\circ} \mathrm{F}=\left(1.8 \times{ }^{\circ} \mathrm{C}\right)+32$

Electrical conductivity is given in millisiemens per meter $(\mathrm{mS} / \mathrm{m})$ unless otherwise specified. Electrical resistivity is given in ohm-meters (ohm-m) unless otherwise specified.

Electrical resistivity ( $\rho$, ohm-m) can be converted to conductivity $(\sigma, \mathrm{mS} / \mathrm{m})$ as follows:

$$
\sigma=\frac{1000}{\rho}
$$

Vertical coordinate information is referenced to the North American Vertical Datum of 1988 (NAVD88) and the Earth Gravitational Model of 1996 (EGM96), as noted in the text and digital data.

Horizontal coordinate information is referenced to North American Datum of 1983 (NAD83), Universal Transverse Mercator projection, Zone 6 North (UTM6N). 


\section{Acronyms Used in This Report:}

$\begin{array}{ll}\text { AEM } & \text { airborne electromagnetic } \\ \text { EM } & \text { electromagnetic } \\ \text { DTM } & \text { digital terrain model } \\ \text { GPS } & \text { global positioning system } \\ \text { IGRF } & \text { International Geomagnetic Reference Field } \\ \text { USGS } & \text { U.S. Geological Survey }\end{array}$

\section{Abbreviations Used in This Report:}

$\mathrm{Hz} \quad$ hertz

$\mathrm{kHz} \quad$ kilohertz

$\mathrm{km} \quad$ kilometer

$\mathrm{m}$ meter

$\max$ maximum

nT nanotesla

ohm-m ohm-meter

ppm parts per million

$\mathrm{mS} \quad$ millisiemen 


\title{
Airborne Electromagnetic and Magnetic Geophysical Survey Data of the Yukon Flats and Fort Wainwright Areas, Central Alaska, June 2010
}

By Lyndsay B. Ball, Bruce D. Smith, Burke J. Minsley, Jared D. Abraham, Clifford I. Voss, Beth N. Astley, Maria Deszcz-Pan, and James C. Cannia

\begin{abstract}
In June 2010, the U.S. Geological Survey conducted airborne electromagnetic and magnetic surveys of the Yukon Flats and Fort Wainwright study areas in central Alaska. These data were collected to estimate the three-dimensional distribution of permafrost at the time of the survey. These data were also collected to evaluate the effectiveness of these geophysical methods at mapping permafrost geometry and to better define the physical properties of the subsurface in discontinuous permafrost areas. This report releases digital data associated with these surveys. Inverted resistivity depth sections are also provided in this data release, and data processing and inversion methods are discussed.
\end{abstract}

\section{Introduction}

Permafrost is prevalent in high-latitude regions throughout the world and can strongly influence the hydrology and ecology of cold regions. Changes in climate are likely to lead to alterations in permafrost distribution, impacting groundwater and surface-water interactions, habitats and ecosystems, man-made infrastructure, and the global carbon cycle (Jorgenson and others, 2001; Nelson and others, 2002; Hinzman, 2005; Walvoord and Striegl, 2007; Froese and others, 2008; Schuur and others, 2008; Rowland and others, 2010). The present-day threedimensional (3-D) distribution of permafrost is poorly constrained, particularly with respect to the variability in total permafrost thickness and the distribution of unfrozen areas, or "taliks." Lack of knowledge of the distribution limits our abilities to build realistic conceptual and numerical models of the groundwater-flow system and groundwater to surface-water interaction. An improved understanding of the current permafrost distribution is essential to improving our understanding of hydrological processes in these regions and to assess the vulnerability of ecosystems, habitats, and infrastructure to climate change.

Mapping permafrost presents particular challenges. Because of the anticipated variability in the spatial distribution of permafrost, direct-sampling techniques such as drilling are not adequate to characterize the extent or thickness, due to the sparsity of such data in cold regions. Logistical problems also exist, as areas characterized by permafrost often have few roads, are ecologically sensitive, and are difficult and costly to access. Geophysical methods provide an alternative to direct sampling and can provide more spatially continuous data with limited overland travel. Geophysical methods measure the variability in subsurface physical properties such as electrical resistivity, permittivity, and seismic velocity. These properties can vary substantially 
between thawed and frozen materials. Due to this contrast in material properties, geophysical measurements can be effective at determining permafrost distribution in the subsurface. By making measurements from an airborne platform, such as a helicopter, data can be collected in ecologically sensitive habitats with minimal impact, over rugged terrain, and in roadless areas common to cold regions.

\section{Purpose and Scope}

In June 2010, the U.S. Geological Survey (USGS) conducted an airborne electromagnetic (AEM) survey of an area near Fort Yukon commonly referred to as Yukon Flats, in central Alaska (fig. 1A). Lines were flown in a block configuration at 350-m line spacing near the town of Fort Yukon (table 1; fig. 1A, block 1). Additional flight lines extend from the block in zigzagging transects to the southwest (block 2, 400.6 total line kilometers) and northeast (block 3, 487.5 total line kilometers). The AEM measurements were used to develop inverse models of the electrical resistivity structure along flight lines. These models, in conjunction with other remote sensing and ground-based data, may provide a foundation for interpreting the distribution of permafrost.

A small AEM survey was also conducted at the Fort Wainwright military facility in Fairbanks, Alaska (fig. 1B). Two 1.5-km lines of AEM data were collected to evaluate the capabilities of the system to map permafrost geometry (extent and depth) and to estimate the permafrost's physical properties (electrical resistivity and dielectric constant).

This report releases digital data from the Yukon Flats and Fort Wainwright study areas. These data and the file structure are explained in the "Geophysical Data Overview" section. The methodology used to collect, process, and invert these data are presented in the "Airborne Electromagnetic and Magnetic Survey: Methods and Measurements" section. Inversions of the data are provided here, but interpretations of these data are beyond the scope of this report and will be presented in future publications.

\section{Description of Study Areas}

\section{Yukon Flats}

The Yukon River drains a large part of central Alaska as well as parts of the Yukon Territory and British Columbia in Canada (fig. 1). The AEM survey was conducted in a portion of the Yukon River basin near Fort Yukon, approximately $225 \mathrm{~km}$ northeast of Fairbanks. This area, known as the Yukon Flats, is characterized by low-relief terrain. Many meandering and braided stream channels are present in the area, including the main channel of the Yukon River and several tributaries. Numerous lakes are found throughout the Yukon Flats and range in size from very small to larger than $5 \mathrm{~km}^{2}$. The shallow geology of the river basin is commonly composed of alluvial gravel underlain by sand and silt, although glacial and eolian deposits may also occur in the area (Brabets and others, 2000, Williams 1962).

Though believed to be present throughout much of the area, permafrost is likely to be absent near active stream channels, and thawed regions may exist near lakes and abandoned stream channels. The most recent map of generalized permafrost distribution and characteristics in Alaska by Jorgenson et al. (2008), indicates nearly all continuous permafrost north of the Yukon River, and discontinuous permafrost south of the Yukon River except for the loess 
plateau, which contains continuous permafrost. Only a single well with measurements of permafrost depth and thickness exists in the entire Yukon Flats area.

Table 1. Flight-line direction and spacing for each survey area.

[na, data not available]

\begin{tabular}{|c|c|c|c|c|c|c|c|c|}
\hline \multicolumn{9}{|c|}{ Yukon Flats study area } \\
\hline $\begin{array}{l}\text { Data } \\
\text { block }\end{array}$ & Description & $\begin{array}{l}\text { Traverse } \\
\text { azimuth } \\
\text { (degrees) }\end{array}$ & $\begin{array}{l}\text { Tie line } \\
\text { azimuth } \\
\text { (degrees) }\end{array}$ & $\begin{array}{l}\text { Traverse } \\
\text { line } \\
\text { spacing } \\
\text { (m) }\end{array}$ & $\begin{array}{l}\text { Tie line } \\
\text { spacing } \\
(\mathrm{km})\end{array}$ & $\begin{array}{l}\text { Traverse } \\
\text { line } \\
\text { distance } \\
(\mathrm{km})\end{array}$ & $\begin{array}{l}\text { Tie line } \\
\text { distance } \\
(\mathrm{km})\end{array}$ & $\begin{array}{c}\text { Total } \\
\text { line } \\
\text { distance } \\
(\mathrm{km})\end{array}$ \\
\hline 1 & $\begin{array}{c}\text { Block near Fort } \\
\text { Yukon } \\
\text { Reconnaissance }\end{array}$ & 050 & 140 & 350 & $\begin{array}{c}16.5 \\
7.5\end{array}$ & 841.9 & 31.5 & 873.4 \\
\hline 2 & $\begin{array}{l}\text { lines southwest } \\
\text { of Fort Yukon }\end{array}$ & variable & na & na & na & 400.6 & na & 400.6 \\
\hline 3 & $\begin{array}{l}\text { Reconnaissance } \\
\text { lines northeast } \\
\text { of Fort Yukon }\end{array}$ & variable & na & na & na & 487.5 & na & 487.5 \\
\hline \multicolumn{9}{|c|}{ Fort Wainwright study area } \\
\hline 1 & All data & 000 & 090 & na & na & 1.5 & 1.5 & 3.0 \\
\hline
\end{tabular}

\section{Fort Wainwright}

The Fort Wainwright study area is located in the western portion of the Fort Wainwright Army Post, immediately east of the city of Fairbanks and north of the Chena River, a tributary to the Tanana River (fig. 1B). The Fort Wainwright area is composed of alluvial deposits containing discontinuous permafrost. The base of the permafrost varies from 10 to over $45 \mathrm{~m}$ (Lawson and others, 1998; Astley and others, 2010). Relict river channels, often deeply thawed, are dispersed across the alluvial surface. A south-facing hill slope at the north end of the study area was previously mapped using outcrops and boreholes as Middle Devonian quartz-muscovite schist and phyllite overlain by loess (Douglas, 2005; Peapples and others, 2000). A Cretaceous age granitic intrusion is exposed approximately 3 miles southeast of the study area (Newberry and Bundtzen 1996). The south-facing hill slope is assumed to be permafrost-free based on numerous boreholes (Astley and Snyder, 2005; Lawson and others, 1998). Also, south-facing hill slopes in the Fairbanks area are generally permafrost- free. 
$\boldsymbol{A}$

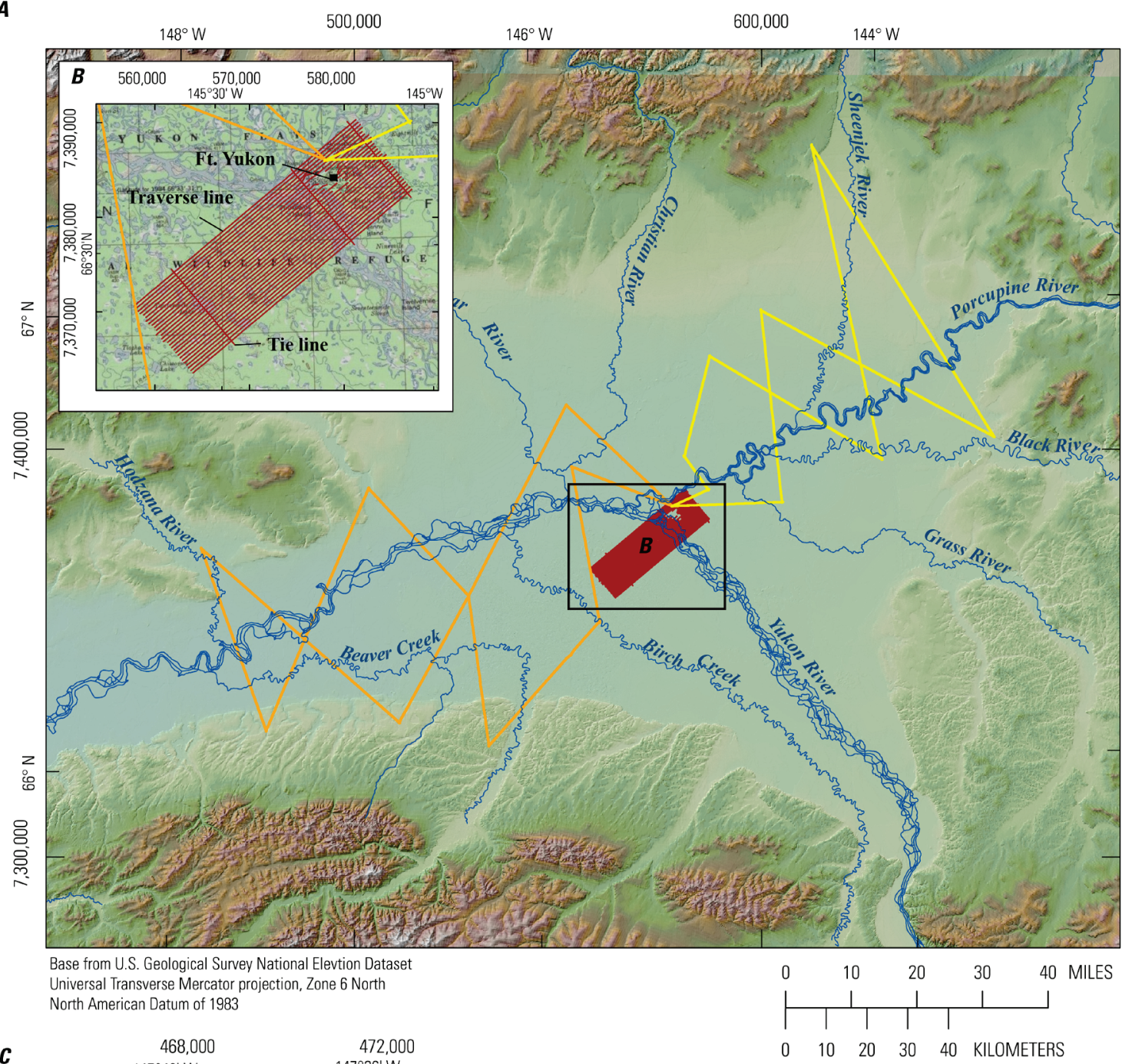

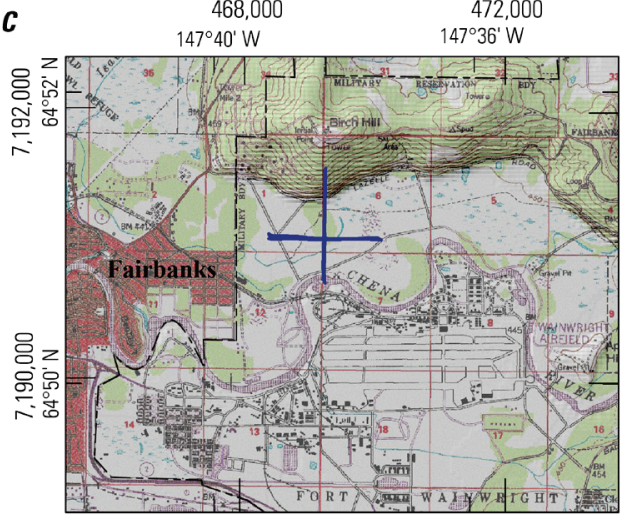

Base from U.S. Geological Survey digital data

Universal Transverse Mercator projection, Zone 6 North

North American Datum of 1983

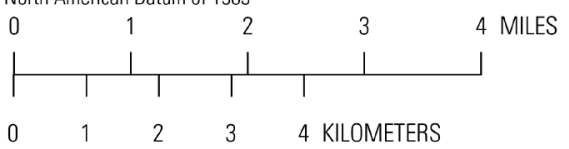

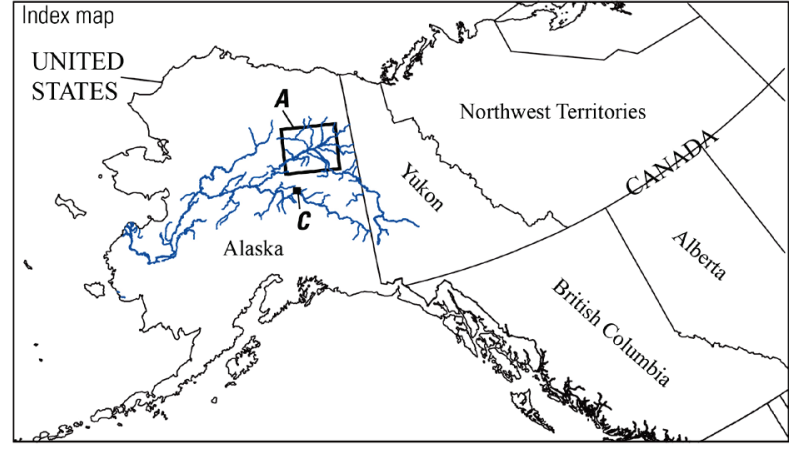

EXPLANATION

Airborne electromagnetic flight line

Yukon Flats study area Ft. Wainwright study area

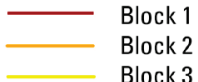

Figure 1. Site maps showing $(A)$ the Yukon Flats, $(B)$ Fort Yukon block, and $(C)$ Fort Wainwright study areas with respect to the Yukon River and its major tributaries. 


\section{Airborne Electromagnetic and Magnetic Survey: Methods and Measurements}

\section{Electromagnetic Measurements}

AEM systems transmit an electromagnetic (EM) signal from an airborne platform that induces secondary currents in the Earth. These secondary currents are subsequently sensed by receiver coils in the sensor housing or "bird" (fig. 2). The measured data are sensitive to the subsurface electrical resistivity structure, which is controlled by lithology and the amount of ice, clay, water, salt, metallic mineralization, and void space in the material. For this study, the RESOLVE helicopter-borne EM system was flown by Fugro Airborne, Ltd. EM measurements were made using six coil pairs that measure signals at separate frequencies from about 400 hertz $(\mathrm{Hz})$ to about $140,000 \mathrm{~Hz}(140 \mathrm{kHz})$. Five of the coil pairs were oriented in a horizontal, coplanar position, and one of the coil pairs was oriented in a vertical, coaxial position. The specific frequencies, separation, and orientation of the coil pairs are given in table 2 . The airborne sensor was flown at a nominal altitude of $30 \mathrm{~m}$ above land surface and was suspended about $30 \mathrm{~m}$ below the helicopter. The EM measurements were made approximately every $3 \mathrm{~m}$ along flight lines. Detailed records of data acquisition and contractor-performed processing are documented in the contractor's report (appendix 1). Principles of AEM methods are summarized by Siemon (2006) and Paine and Minty (2005).

The depth of investigation of all EM systems is dependent on the EM frequency, coil orientation, system elevation above ground surface, data errors, and the electrical resistivity of the subsurface. One estimate of the depth of investigation for the frequencies used in the RESOLVE system is shown in figure 3. In this figure, the depth of investigation is defined as one-half of the skin depth (the point at which a plane electromagnetic wave has attenuated to 37 percent of the initial amplitude). The depth of investigation estimates shown in figure 3 are conservative because one skin depth generally is considered to be the depth limit of AEM measurements (Fraser, 1978). Generally, at the highest frequency, depths of investigation are just a few meters. At the lowest frequency, $400 \mathrm{~Hz}$, the depth of investigation may be on the order of 80 $\mathrm{m}$. This aspect of AEM measurements is the basic principle that allows depth images to be constructed. Additional discussion of the depth of investigation can be found in the subsequent section "Model Assessment Using the Depth of Investigation (DOI) Metric."

The EM signals were recorded for each frequency as in-phase and quadrature (out-of-phase) responses as referenced to the transmitted signal. These signals were post-processed to apparent resistivity for each frequency and a corresponding apparent depth as described by Fraser (1978). The apparent resistivity is an estimated material property based on assumptions of the measurement and of a homogeneous Earth (Fraser, 1978); it does not represent the heterogeneous or anisotropic resistivity structure common to geology. Estimates of the intrinsic resistivity are obtained through a variety of imaging methods that are described by Farquharson and others (2003), Hodges (2004), and Siemon (2006). The differential resistivity and depth transformation (Huang and Fraser, 1996) is one simple depth imaging method that has proven effective for AEM survey data from other study areas (Smith and others, 2003). Both the apparent resistivity and differential data are given in the digital line-data files (see the README file in the LINEDATA folder).

An important part of the data processing is leveling the EM signals for system drift and calibrations. The specific steps used in the data processing are described in appendix 1 . The digital line data provide the raw in-phase and quadrature data, and the processed data from which the 
apparent resistivity was computed. The final leveled data are also provided. These data are included in the database in case the original data are used for reprocessing.
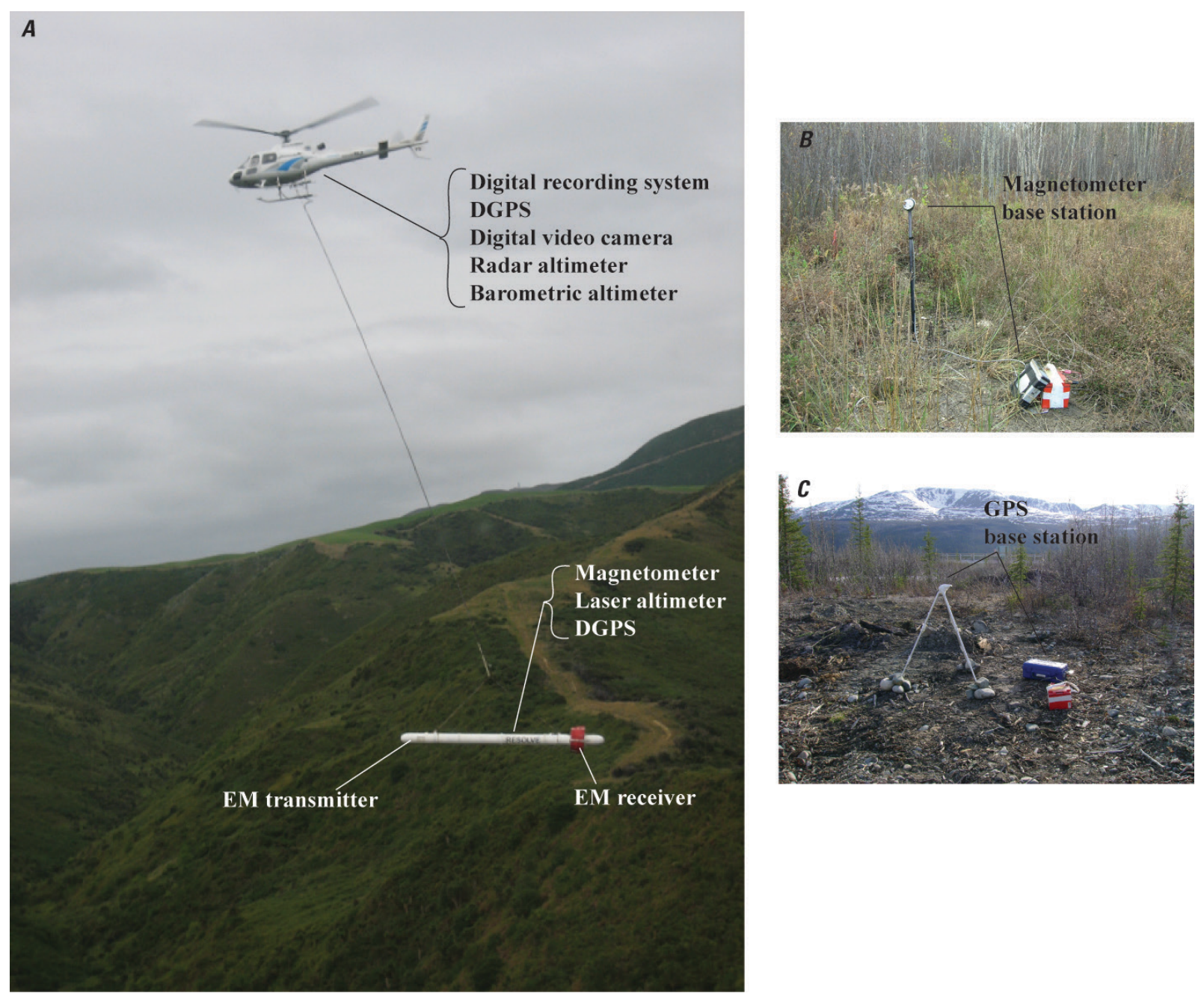

Figure 2. Helicopter-borne RESOLVE geophysical system used during this study. Electromagnetic, magnetic, and laser altimeter sensors are housed in a "bird," a cigar-shaped 9-m-long tube, which is flown at approximately $30 \mathrm{~m}$ above the land surface. Modified from the Fugro contractor's report (appendix 1) and Smith and others (2010). DGPS, differentially corrected global positioning system; EM, electromagnetic. 
Table 2. Frequencies and measurement sensitivities for the airborne electromagnetic survey.

\begin{tabular}{ccccc}
\hline Coil configuration & $\begin{array}{c}\text { Coil } \\
\text { separation } \\
(\mathbf{m})\end{array}$ & $\begin{array}{c}\text { Nominal } \\
\text { frequency }(\mathbf{H z})\end{array}$ & $\begin{array}{c}\text { Actual } \\
\text { frequency }(\mathbf{H z})\end{array}$ & $\begin{array}{c}\text { Sensitivity } \\
\text { (parts per million) }\end{array}$ \\
\hline Vertical coaxial & 9.0 & 3,300 & 3,260 & 0.24 \\
Horizontal coplanar & 7.9 & 390 & 378 & 0.12 \\
Horizontal coplanar & 7.9 & 1,800 & 1,843 & 0.12 \\
Horizontal coplanar & 7.9 & 8,200 & 8,180 & 0.24 \\
Horizontal coplanar & 7.9 & 40,000 & 40,650 & 0.44 \\
Horizontal coplanar & 7.9 & 140,000 & 128,510 & 0.44 \\
\hline
\end{tabular}

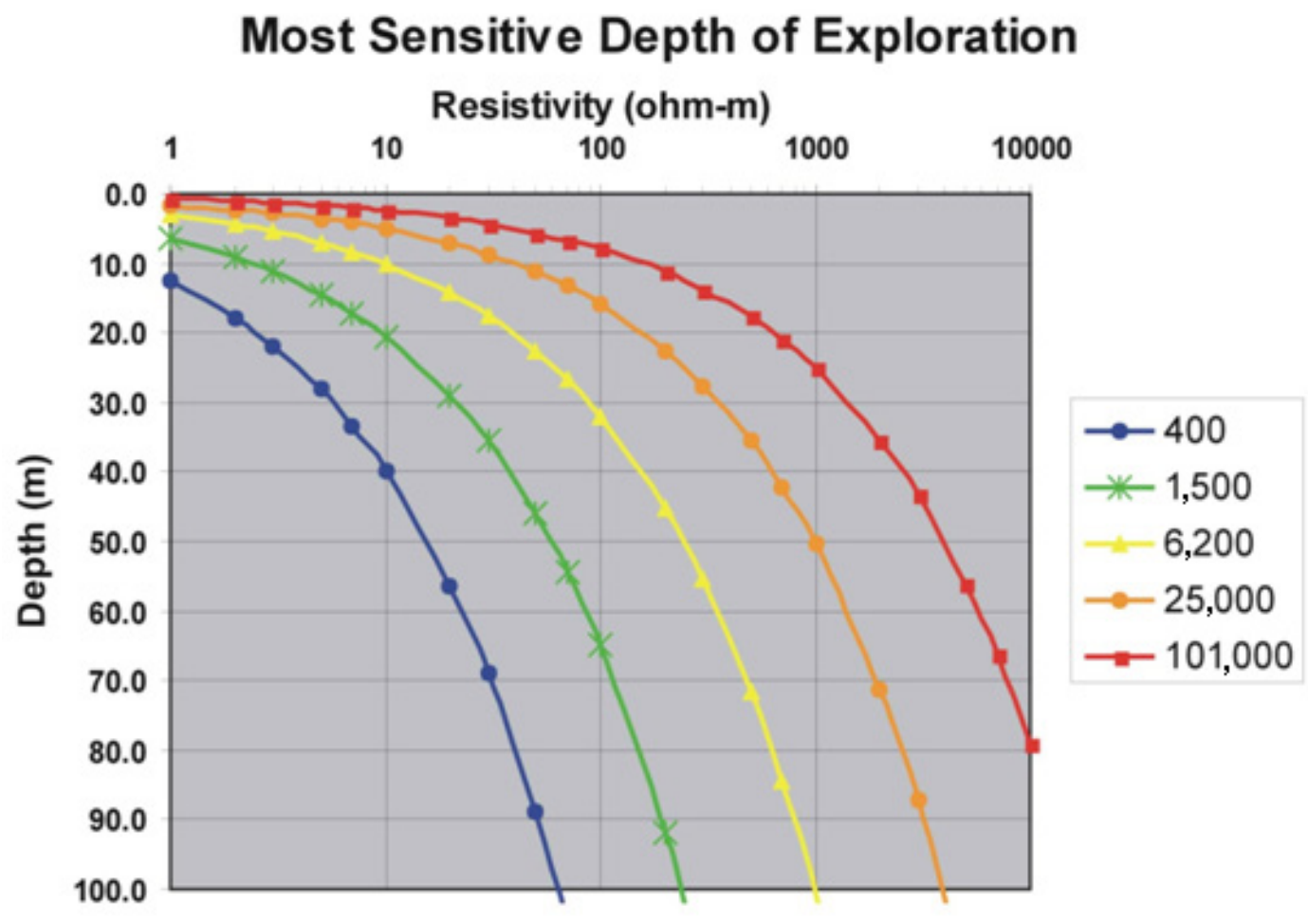

Figure 3. Depth of penetration or imaging as a function of frequency and Earth resistivity for the RESOLVE system (Greg Hodges, Fugro Airborne, Ltd., written commun., 2004). 


\section{Total Magnetic Field Measurements}

The AEM survey used a Scintrex CS-3 single-cell cesium vapor magnetic sensor that measures the Earth's total magnetic field to an accuracy of 0.01 nanotesla (nT). The magnetic field consists of the Earth's main magnetic field and the local magnetic field due to sources within the crust and ferromagnetic metallic sources at the surface. The total field measurements are influenced by short-term variations in the magnetic field that are independent of local sources and are caused mainly by solar activity. A total magnetic field base station, set up by the contractor near the base of operations, was used to record these short-term variations in the Earth's total magnetic field, which were subtracted from the measurements made during the survey. Sharma (2002) describes the basic principles of the main magnetic field removal from magnetometer measurements. The contractor also processed the total magnetic field to remove the spatial variation from the Earth's main magnetic field. This spatial variation is defined by the International Geomagnetic Reference Field (IGRF).

\section{Ancillary Measurements}

The AEM system also monitors $60-\mathrm{Hz}$ signals generally associated with cultural noise. These data are given as the HZ60 channel in the line database (LINEDATA folder). The data are given as arbitrary voltage levels, which generally increase over power lines. The expression of power lines is quite variable due to a number of factors such as the size of the line, how well it is electrically grounded, and the electrical resistivity of the Earth. In general, the infrastructure around urban development, transmission towers, and along major roads results in higher cultural noise levels and high $60-\mathrm{Hz}$ signals.

Positioning measurements of the AEM sensors and the helicopter are critical in data processing and making accurate maps. Location data from the global positioning system (GPS) in both the bird and helicopter are given in the files in the LINEDATA folder. Horizontal coordinates are presented in the Universal Transverse Mercator projection, Zone 6 North (UTM6N), relative to the North American Datum of 1983. Elevation data derived from the laser altimeter on the sensor as well as the radar and barometric altimeters on the helicopter are relative to the Earth Gravitational Model of 1996 (EGM96) and referenced to the World Geodetic System of 1984 (WGS84).

\section{Inversion of Electromagnetic Data}

The multifrequency AEM data were inverted using the code EM1DFM (Farquharson, 2000; Farquharson and others, 2003). This is a 1-D nonlinear least-squares algorithm that recovers the distribution of electrical conductivity (reciprocal of resistivity) with depth beneath each sounding. The inversion algorithm minimizes an objective function $(\Phi)$ that is a combined measure of data misfit $\left(\phi_{d}\right)$ and model norm $\left(\phi_{m}\right)$ given by equation 1:

$$
\Phi=\phi_{d}+\beta \phi_{m}
$$

Inversion of AEM data is ill-posed and nonunique; that is, many resistivity models are consistent with the measured data, and some form of regularization is needed to stabilize the inverse problem. Regularization is introduced through the model norm, which favors specific properties in the inverted model such as proximity to a reference model or smoothness. The relative importance of fitting the data compared to controlling the model through regularization 
is controlled by a trade-off parameter $(\beta)$. Details on how $\beta$ was chosen for the inversions in this study are discussed in appendix 2 .

The data misfit component of the objective function describes how well the observed data match the data predicted by the inverted resistivity model. Specifically, it is defined as the L2norm of the difference between observed and predicted data, $d^{\text {obs }}$ and $d^{\text {pred }}$, normalized by the data error, for each frequency.

$$
\phi_{d}=\left\|W_{d}\left(d^{\text {obs }}-d^{\text {pred }}\right)\right\|^{2}
$$

The data weighting operator, $W_{d}$, is a diagonal matrix with entries $\sigma_{f}^{-1}$, where $\sigma_{f}$ is the standard deviation of the noise for each frequency. Specification of the data errors is an important, but often overlooked, aspect of the inverse problem. Set too low, the algorithm will tend to fit noise in the data and result in models with too much structure. Set too high, the algorithm can easily fit the data with many models, and the resulting models are strongly controlled by the regularization term. Data errors used for inversion were taken as 6 percent of the data amplitude for each frequency and its in-phase and quadrature components. This level of noise was assessed from the data using the algorithm of Minsley (2011), which was also used to calculate calibration factors, as discussed in appendix 2. By choosing a percentage error, rather than fixed error values (Smith and others, 2010), more appropriate data misfits are obtained over both resistive and conductive regimes.

The model norm component of the objective function is a combined measure of proximity to a reference model, $m^{\text {ref }}$, and smoothness.

$$
\phi_{m}=\alpha_{s}\left\|m-m^{r e f}\right\|^{2}+\alpha_{z}\|\nabla m\|^{2}
$$

The scaling terms ${ }^{\alpha_{s}}$ and $\alpha_{z}$ control the relative importance given to proximity to the reference model and model smoothness, respectively. Because $\beta$ scales both ${ }^{\alpha_{s}}$ and $\alpha_{z}$ in equation 1, it is only important to specify the relative weight of these latter terms, which is often simplified by setting one of them to 1 .

The inversion parameter settings used on the Yukon Flats and Fort Wainwright AEM data are summarized in tables 3 and 4 . Appendix 2 provides a brief discussion of how these settings were selected. 
Table 3. Layer thicknesses used for airborne electromagnetic inversions.

\begin{tabular}{cc}
\hline Layer & $\begin{array}{c}\text { Thickness } \\
(\mathbf{m})\end{array}$ \\
\hline 1 & 1.20 \\
2 & 1.37 \\
3 & 1.55 \\
4 & 1.76 \\
5 & 1.99 \\
6 & 2.26 \\
7 & 2.56 \\
8 & 2.91 \\
9 & 3.30 \\
10 & 3.74 \\
11 & 4.24 \\
12 & 4.81 \\
13 & 5.45 \\
14 & 6.18 \\
15 & 7.01 \\
16 & 7.95 \\
17 & 9.02 \\
18 & 10.22 \\
19 & 11.59 \\
20 & 13.15 \\
21 & 14.91 \\
22 & 16.91 \\
23 & 19.18 \\
24 & 21.75 \\
25 & infinity \\
\hline &
\end{tabular}

Table 4. Summary of inversion parameters used in EM1DFM.

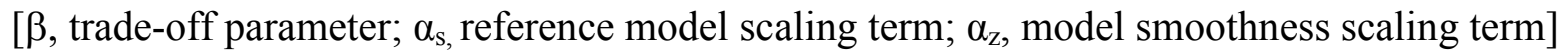

\begin{tabular}{cc}
\hline Parameter & Setting \\
\hline Model type & Conductivity only \\
Starting conductivity & 25 layers, $175 \mathrm{~m}$ to the top of the half-space, best-fitting \\
model & conductivity \\
Base reference model & 28 ohm-m \\
Inversion type & Fixed tradeoff $(\beta=3)$ \\
Model norm & $\alpha_{\mathrm{s}}=0.01, \alpha_{\mathrm{z}}=1$ \\
components & \\
\hline
\end{tabular}




\section{Model Assessment Using the Depth of Investigation (DOI) Metric}

The depth of investigation (DOI) metric (Oldenburg and Li, 1999) is a valuable tool for evaluating the approximate depth in an inverted model to which the data are sensitive. The DOI metric is defined as the difference between two models inverted with different reference models, divided by the difference in reference models.

$$
D O I=\frac{m^{1}-m^{2}}{m_{0}^{1}-m_{0}^{2}}
$$

Because EM1DFM solves for log-conductivity values, we use $m=\log _{10} \sigma$ to compute the DOI metric. Where the inverted models, $m^{1}$ and $m^{2}$, are strongly determined by the data (that is, shallow regions with greater sensitivity), $m^{1} \approx m^{2}$ and $D O I \rightarrow 0$. At depth where the data are not sensitive to the model parameters, regularization in the inverse problem forces the inverted model to be close to the reference model so that $m^{1} \approx m_{0}^{1}, m^{2} \approx m_{0}^{2}$, and $D O I \rightarrow 1$. Small values of the DOI metric, therefore, represent regions in the model that are most strongly determined by the data.

To compute the DOI metric, additional inversions are run with reference models $m_{0}^{1}=5.6$ ohm-meters and $m_{0}^{2}=140 \mathrm{ohm}$-meters, which are scaled by a factor of 5 from the base reference model of 28 ohm-meters. A cutoff value for the DOI metric is specified such that portions of the inverted models with DOI values greater than the cutoff are strongly influenced by the reference model. In this study, we use $D O I_{\text {cutoff }}=0.2$.

The DOI metric is a very useful tool when displaying the final inverted images because it provides a means for displaying areas of confidence in the model. In many instances, geophysical images are presented without any measure of where the models are determined by the data and where they are simply a reflection of the reference model. A simple approach is to completely blank-out regions in the model where $D O I>D O I_{\text {cutoff }}$, preserving only the parts of the model that are controlled by the measured data. This procedure has been applied to the inverted resistivity data provided in the SECTIONDATA folder under the RES_INV_DOI channel.

\section{Deriving Calibration Factors for the Airborne Electromagnetic Data}

Correcting systematic data errors is a key step in achieving reliable and interpretable inversion models (Deszcz-Pan and others, 1998). During inversion of the original uncalibrated data, target misfits could not be achieved and biases were observed on several of the residuals (that is, data were always under- or over-predicted for certain frequencies). To address this issue, we adapted the calibration model of Deszcz-Pan and others (1998):

$$
d_{o b s}^{I}+j d_{o b s}^{Q}=G e^{j \phi}\left(d^{I}(m)+j d^{Q}(m)+B^{I}+B^{Q}\right)
$$

Here, $d_{o b s}^{I}$ and $d_{o b s}^{Q}$ represent the in-phase and quadrature observed data at each frequency, and $d^{I}(m)$ and $d^{Q}(m)$ are the in-phase and quadrature components of the predicted data for an Earth model $(m)$. The calibration factors that are calculated for each frequency include gain $(G)$, phase $(\phi)$, in-phase bias $\left(B^{I}\right)$, and quadrature bias $\left(B^{Q}\right)$. In their original work, 
Deszcz-Pan and others (1998) used ground-based well and geophysical data as the known Earth models $(m)$. Using the forward geophysical response to these known models, the four calibration factors for each frequency were computed using a nonlinear least-squares algorithm.

In the Yukon Flats survey, there is not sufficient ground-based data to derive known models that can be used in the calibration procedure. Instead, an alternate approach to calibration was developed that uses airborne data acquired over the same profile at multiple elevations, with no requirement for a known Earth model (Minsley and others, 2011). The multi-elevation calibration method works by using all of the data from different elevations over a single location to calculate the unknown gain, phase, and bias calibration parameters, along with the single unknown Earth model at that location. These parameters, along with their uncertainty, are calculated using the stochastic algorithm of Minsley (2011). Once the calibration factors are calculated, a corrected dataset is calculated by applying the calibration factors to the original observed data according to

$$
d_{c o r r}^{I}+j d_{d c o r r}^{Q}=\frac{1}{G} e^{-j \phi}\left(d_{o b s}^{I}+j d_{o b s}^{Q}\right)-B^{I}-B^{Q}
$$

Data were acquired along a portion of flight line L10220 (Yukon Flats survey) at nominal elevations of 30,40 , and $50 \mathrm{~m}$. Calibration parameters were assessed at multiple locations along this profile, as well as using data from a single elevation over a conductive lake along flight line L10020. The best set of calibration factors that were consistent with all of the datasets are summarized in table 5. A discussion of the selection of these parameters is provided in appendix 2. Inversions run using the calibration-corrected dataset resulted in substantially improved data misfits over the entire survey area and reduced biases on individual components of the data residuals.

Table 5. Derived calibration parameters.

\begin{tabular}{ccccc}
\hline $\begin{array}{c}\text { Frequency } \\
(\mathbf{H z})\end{array}$ & Gain & $\begin{array}{c}\text { Phase } \\
\text { (degrees) }\end{array}$ & $\begin{array}{c}\text { Bias } \\
\text { (in phase, } \\
\text { parts per } \\
\text { million) }\end{array}$ & $\begin{array}{c}\text { Bias } \\
\text { (quadrature, } \\
\text { parts per million) }\end{array}$ \\
\hline 400 & 1.00 & 0.14 & -2.56 & -2.70 \\
1,800 & 0.95 & 0.05 & -2.06 & 4.80 \\
3,300 & 0.98 & 0.04 & 4.25 & 7.45 \\
8,200 & 0.90 & 0.40 & -4.81 & -15.28 \\
$40 \mathrm{k}$ & 0.99 & 0.25 & -1.16 & -29.20 \\
$140 \mathrm{k}$ & 1.01 & 0.37 & -24.51 & 3.43 \\
\hline
\end{tabular}

\section{Geophysical Data Overview}

Digital data are provided with this report for the Yukon Flats and Fort Wainwright study areas. Because of the different objectives and spatial extents at each study area, the data release differs between the two areas. For the Yukon Flats area, several products and data formats have been provided. These products and their file structure are summarized in table 6 and described in the following sections. For the Fort Wainwright area, a more limited number of products has been created (table 7). In addition to these products, Astley and other's (2010) presentation 
comparing the Fort Wainwright AEM data to borehole and ground geophysical data has also been included as appendix 3 . The following sections describe the digital data in more detail.

Table 6. Digital data organization and description for files and folders for the Yukon Flats study area.

\begin{tabular}{|c|c|}
\hline Folder & Description \\
\hline METADATA & Metadata description of digital data. \\
\hline SECTIONDATA & $\begin{array}{l}\text { Databases of the inverted resistivity depth sections in ASCII standard (*.xyz) and Geosoft } \\
\text { Oasis montaj }{ }^{1}\left({ }^{*} . \mathrm{gdb}, \text { http://www.geosoft.com/) database formats. }\right.\end{array}$ \\
\hline FLIGHTLINE & $\begin{array}{l}\text { Geospatial information consisting of survey flight lines (FLIGHT_LINES). Subdirectories } \\
\text { exist for AutoCAD files (LINE_DXF folder, *.dxf), shape files (LINE_SHP folder, *.shp), } \\
\text { and keyhole markup language }{ }^{2} \text { (LINE_KML, *.kml) formats. }\end{array}$ \\
\hline GRIDS & $\begin{array}{l}\text { Gridded geophysical and ancillary data created by the contractor (FUGRO folder) and } \\
\text { USGS (USGS folder). All grids are in Geosoft Oasis montaj }{ }^{1} \text { (GRID_GRD folder, *.grd) } \\
\text { format, a standard of the geophysical industry used in many map display computer } \\
\text { programs. USGS grids are also provided as georeferenced images in geoTIFF format } \\
\text { (GRID_GEOTIFF folder, *.tif). }\end{array}$ \\
\hline LINEDATA & $\begin{array}{l}\text { AEM data in ASCII standard }\left({ }^{*} . \mathrm{xyz}\right) \text { and Geosoft Oasis montaj }{ }^{1}\left({ }^{*} . \mathrm{gdb}\right) \text { database formats. } \\
\text { The README file in this directory contains channel heading descriptions. }\end{array}$ \\
\hline PLOTS & Images of inverted resistivity sections (*.pdf). \\
\hline \multicolumn{2}{|c|}{$\begin{array}{l}{ }^{1} \text { Information on the Oasis montaj program and a free data viewer can be found at } \\
h t t p: / / w w w . g e o s o f t . c o m / \\
{ }^{2} \text { Information on the keyhole markup language format and free GoogleEarth software can be } \\
\text { found at } h t t p: / / w w w . g o o g l e . c o m / e a r t h / i n d e x . h t m l\end{array}$} \\
\hline
\end{tabular}

Table 7. Digital data organization and description for files and folders for the Fort Wainwright study area.

\begin{tabular}{|c|c|}
\hline Folder & Description \\
\hline METADATA & Metadata description of digital data. \\
\hline SECTIONDATA & $\begin{array}{l}\text { Databases of the inverted resistivity depth sections in ASCII standard }(* . \mathrm{xyz}) \text { and Geosoft } \\
\text { Oasis montaj }{ }^{1}\left({ }^{*} . \mathrm{gdb}, \text { http://www.geosoft.com/) database formats. }\right.\end{array}$ \\
\hline FLIGHTLINES & $\begin{array}{l}\text { Geospatial information consisting of survey flight lines (FLIGHT_LINES). Subdirectories } \\
\text { exist for AutoCAD files (LINE_DXF folder, *.dxf), shape files (LINE_SHP folder, *.shp), } \\
\text { and keyhole markup language }{ }^{2} \text { (LINE_KML, * .kml) formats. }\end{array}$ \\
\hline LINEDATA & $\begin{array}{l}\text { AEM data in ASCII standard }(* . x y z) \text { and Geosoft Oasis montaj }{ }^{1}(* \text {.gdb) database formats. } \\
\text { The README file in this directory contains channel heading descriptions. }\end{array}$ \\
\hline
\end{tabular}

${ }^{1}$ Information on the Oasis montaj program and a free data viewer can be found at http://www.geosoft.com/

${ }^{2}$ Information on the keyhole markup language format and free GoogleEarth software can be found at http://www.google.com/earth/index.html 


\section{Metadata}

The METADATA folder contains files that describe geophysical survey blocks (fig. 1), including spatial information on datums and projections.

\section{Flight Lines}

The FLIGHTLINE folder contains geospatial datasets of the flight-line paths. The flightline location files are formatted in AutoCAD format (LINE_DXF folder, *.dxf), Esri Shapefile format (LINE_SHP folder, *.shp and associated files), and in GoogleEarth keyhole markup language format (LINE_KML folder, *.kml).

\section{Line Data}

The AEM survey data are given in the folder LINEDATA. The files are given in ASCII format with column headings as described in the README file. The contractor's report in appendix 1 also describes the digital flight-line data.

\section{Section Data}

The resistivity structure as a function of depth along the flight lines, as determined from the previously described inversion process, is given in the folder SECTIONDATA. The DOI cutoff has been applied to the inverted resistivity values provided in the RES_INV_DOI channel. The depth intervals for each inverted model layer (DEP_TOP and DEP_BOT channels) are relative to land-surface elevation. One important aspect of the geographic plotting of section data is choosing an appropriate representation of the land-surface elevation. Elevation data are provided relative to two datums. The DTM_AEM channel is based on processed GPS and laser altimeter values and is referenced to EGM96. The processing steps taken to prepare these elevations are described by FUGRO in appendix 1. Because these elevations are derived from auxiliary measurements taken during the AEM survey, the resolution is comparable to the AEM data and may best represent the shape of the land surface. However, these elevations are available only along flight lines. To facilitate comparison of the inverted resistivity profiles to other data beyond flight lines, such as borehole lithology or remote sensing data, elevations in the inverted resistivity databases have also been sampled from the $60-\mathrm{m}$ resolution National Elevation Dataset (http://ned.usgs.gov/), which is referenced to NAVD88.

\section{Grids}

Various channels of the flight-line data from the Yukon Flats area were interpolated onto regular grids, commonly referred to as "gridding," to produce map plots. One of the challenges of gridding airborne geophysical data is that the spacing between flight lines (100s of meters or more) is much greater than the sampling down-line (a few meters). Specialized gridding methods have been developed to deal with this aspect of processing airborne geophysical data (Smith and O'Connell, 2005). The contractor has used a modified Akima spline method (appendix 1). The contractor grids are given in the FUGRO subfolder. These grids have not been modified. The nomenclature for the grid names is given in the README file.

An alternate gridding method is the minimum curvature method implemented by Webring (1981) for geophysical airborne data. This gridding method is implemented in Geosoft's Oasis montaj program (http://www.geosoft.com/resources/technology-papers/solution- 
earth-modeling). We have used this algorithm to produce 75-m-resolution grids from selected channels of the flight-line data from Yukon Flats: apparent resistivity at each frequency, residual magnetic field, and land-surface elevation defined by the AEM survey. In addition to these data channels, inverted resistivity data from each model layer have also been gridded at $75-\mathrm{m}$ resolution. These grids can be found in the USGS subfolder.

All USGS-generated grids are provided in two formats: Geosoft grid format (GRID_GRD folder, *.grd) and georeferenced geoTIFF images (GRID_GEOTIFF, *.tif). The Geosoft grids can be viewed and analyzed in free software distributed by Geosoft (http://www.geosoft.com/pinfo/oasismontaj/free/montajviewer.asp) or in various other mapping software packages using free plug-ins provided by Geosoft (http://www.geosoft.com/downloads). For example, the Geosoft-formatted grids can be viewed directly in the ESRI ArcMap application with the Geosoft ArcGIS plug-in (http://www.geosoFortcom/support/downloads/plug-ins/plug-arcgis). A sample display of one such plot in ArcMap is shown in fig. 4. Once the plug-in is installed and loaded in ArcMap, Geosoft grids can be handled within ArcMap in a similar manner to other types of raster data. GeoTIFF images can be viewed geospatially in most standard geographic information system software. The geoTIFF files can also be opened in several standard image-viewing software packages, including Windows Picture and Fax Viewer. 


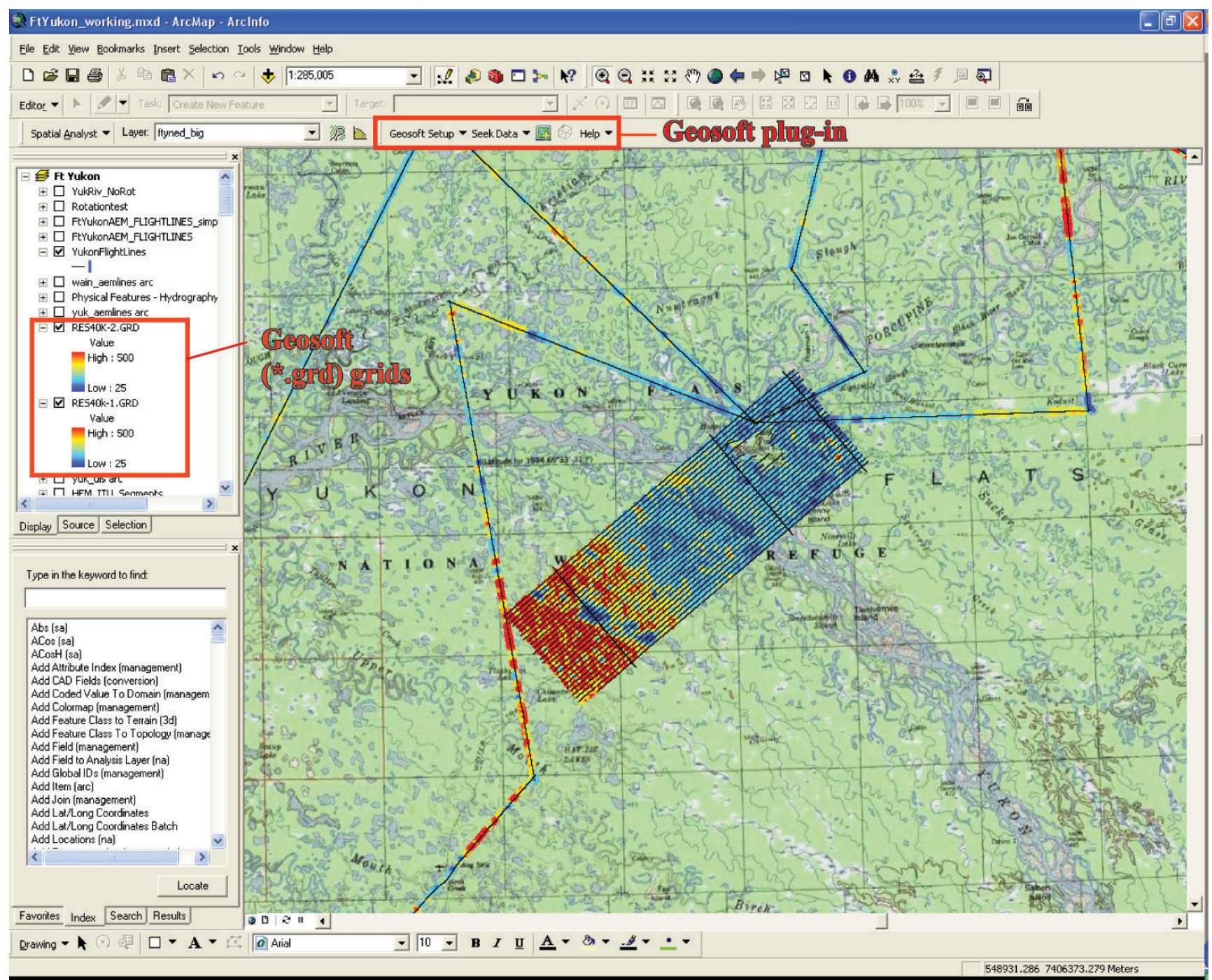

Figure 4. Screen shot of the ESRI application ArcMap being used to display Geosoft grids. Note the Geosoft plug-in is displayed in the toolbar. The background topographic relief map is displayed using data added by Internet servers.

\section{Plots}

Plots of the inverted resistivity sections have been generated for all flight lines in the Yukon Flats study area (PLOTS folder). The DTM_AEM channel in the YukonFlatsAEM_INV database was selected for vertical referencing because it most accurately represents the topography of the land surface at the scale of the inverted models. The index map panel shows the location of the selected flight line being displayed in a given plot. The plot files have been produced with a common color scale for all sections to allow comparison between flight lines. Plots of the Fort Wainwright geophysical data are given by Astley and others (2010) as a poster presentation included in appendix 3. 


\section{Acknowledgments}

AEM data collection, processing, and inversion of the Yukon Flats AEM study were funded by the USGS Climate Effects Network Project and the USGS Mineral Resources Integrated Methodology Project. Funding for the Fort Wainwright airborne geophysical project was as follows: Costs for data acquisition were shared by Fugro Airborne Surveys, Ltd., and the USGS Mineral Resources Integrated Methodology Project. The U.S. Army Cold Regions Research and Engineering Laboratory funded processing of the data. Ground resistivity and borehole data were leveraged from existing projects funded by the U.S. Army Environmental Command in cooperation with U.S. Army Garrison Alaska. The authors thank the Fugro staff for their efforts in the collection of these data. In particular, we acknowledge the field crew: Glen Charbonneau, Manu Chaudry, Will Harper, and Mitch Jackson. 


\section{References Cited}

Astley, B.N., Smith, B.D., Hodges, Greg, Snyder, C.S., and Abraham, J.D., 2010, Application of helicopter electromagnetics as part of an integrated program to map permafrost, Fairbanks, Alaska [abs.]: American Geophysical Union, San Francisco, Calif., 2010 Fall Meeting, Abstract NS31A-1388, 1 p.

Asltey, B.N., and C.S. Snyder, 2005, Operable Unit 3 permafrost resistivity investigation, Fort Wainwright, Alaska: U.S. Army Cold Regions Research and Engineering Laboratory Letter Report 05-10, $35 \mathrm{p}$.

Brabets, T.P., Wang, Bronwen, and Meade, R.H., 2000, Environmental and hydrologic overview of the Yukon River basin, Alaska and Canada: U.S. Geological Survey Water-Resources Investigation Report 99-4204, 106 p.

Deszcz-Pan, Maria, Fitterman, D.V., and Labson, V.F., 1998, Reduction of inversion errors in helicopter EM data using auxiliary information: Exploration Geophysics, v. 29, p. 142-146.

Douglas, T.A., 2005, Geologic setting of the Birch Hill Tank Farm Operable Unit 3, Fort Wainwright, Alaska: U.S. Army Cold Regions Research and Engineering Laboratory Letter Report 05-1, $32 \mathrm{p}$.

Farquharson, C.G., 2000, Background for program "EM1DFM": Vancouver, Canada, University of British Columbia Geophysical Inversion Facility, 20 p., accessed August 2010 at http://www.eos.ubc.ca/ubcgif/iag/sftwrdocs/emldfm/bg.pdf.

Farquharson, C.G., Oldenburg, D.W., and Routh, P.S., 2003, Simultaneous 1D inversion of looploop electromagnetic data for magnetic susceptibility and electrical conductivity: Geophysics, v. 68 , no. 6 , p. $1857-1869$.

Fraser, D.C., 1978, Resistivity mapping with an airborne multicoil electromagnetic system: Geophysics, v. 43, p. 144-172.

Froese, D.G., Westgate, J.A., Reyes, A.V., Enkin, R.J., and Preece, S.J., 2008, Ancient permafrost and a future, warmer Arctic: Science, v. 321, p. 1648.

Hinzman, L.D., Bettez, N.D., Bolton, W.R., Chaplin, F.S., and others, 2005, Evidence and implications of recent climate change in northern Alaska and other Arctic regions: Climatic Change, v. 72, p. 251-298.

Hodges, Greg, 2004, Practical inversions for helicopter electromagnetic data: Proceedings, Symposium on the Application of Geophysics to Engineering and Environmental Problems, Environmental and Engineering Geophysical Society, $10 \mathrm{p}$.

Huang, Haoping, and Fraser, D.C, 1996, The differential parameter method for multifrequency airborne resistivity mapping: Geophysics, v. 55, p. 1327-1337.

Jorgenson, M.T., Racine, C., Walters, J., and Osterkamp, T., 2001, Permafrost degradation and ecological changes associated with a warming climate in central Alaska: Climatic Change, v. 48 , p. $551-579$.

Jorgenson, Torre, Yoshikawa, Kenji, Kanevskiy, Mikhail, Shur, Yuri, Romanovsky, Vladimir, Marchenko, Sergei, Grosse, Guido, Brown, Jerry, and Jones, Ben, 2008, Permafrost characteristics of Alaska (map), Institute of Northern Engineering, University of Alaska Fairbanks.

Lawson, D.E., Arcone, S.A., Delaney, A.J., Strasser, J.D., Strasser, J.C., Williams, C.R., and Hall, T.J., 1998, Geological and geophysical investigations of the hydrogeology of Fort Wainwright, Alaska, Part II: North central Cantonment area: U.S. Army Cold Regions Research and Engineering Laboratory Report 98-6, 65 p. 
Minsley, B.J., 2011, A trans-dimensional Bayesian Markov chain Monte Carlo algorithm for model assessment using frequency-domain electromagnetic data: Geophysical Journal International, doi:10.1111/j.1365-246X.2011.05165.x.

Minsley, B.J., Hodges, Greg, Smith, B.D., and Abraham, J.D., 2011, Multi-elevation calibration of frequency-domain electromagnetic data: 24th Symposium on the Application of Geophysics to Engineering and Environmental Problems, Charleston, S.C., 1 p.

Nelson, F.E., Anisimov, O.A., and Shiklomanov, N.I., 2002, Climate change and hazard zonation in the circum-Arctic permafrost regions: Natural Hazards, v. 26, p. 203-225.

Newberry, R.J., and Bundtzen, T.K., 1996, Preliminary geologic map of the Fairbanks mining district, Alaska: Alaska Division of Geological and Geophysical Surveys, Public Data File 96-16, scale 1:63,360.

Oldenburg, D.W., and Li, Yaoguo, 1999, Estimating depth of investigation in de resistivity and IP surveys: Geophysics, v. 64, no. 2, p. 403-416.

Paine, J.G., and Minty, B.R.S., 2005, Airborne hydrogeophysics, in Rubin, Yoram, and Hubbard, S.S., eds., Hydrogeophysics: The Netherlands, Springer, Water Science and Technology Library, v. 50, p. 333-357.

Peapples, P.R., Astley, B.N., Lawson, D.E., Bigl, S.A., Snyder, C.F., Staples, Ann, Wilkinson, J.H., and Epps, S.A., 2000, Bedrock and structure characterization: Birch Hill tank farm and truck fill stand, Fort Wainwright, Alaska: U.S. Army Cold Regions Research and Engineering Laboratory Letter Report 00-11, 36 p.

Rowland, J.C., Jones, C.E., Altmann, G., Bryan, R., Crosby, B.T., Geernaert, G.L., Hinzman, L.D., Kane, D.L., Lawrence, D.M., Mancino, A., Marsh, P., McNamara, J.P., Romanovsky, V.E., Toniolo, H., Travis, B.J., Trochim, E., and Wilson, C.J., 2010, Arctic landscapes in transition: Responses to thawing permafrost: EOS Transactions of the American Geophysical Union, v. 91, p 229-236.

Schuur, E.A.G., Bockheim, James, Canadell, J.G., Euskirchen, Eugiene, Field, C.B., Goryachkin, S.V., Hagemann, Stefan, Kuhry, Peter, Lafleur, P.M., Lee, Hanna, Mazhitova, Galina, Nelson, F.E., Rinke, Annette, Romanovsky, V.E., Shiklomanov, Nikolay, Tarnocai, Charles, Venevsky, Sergey, Vogel, J.G., and Zimov, S.A., 2008, Vulnerability of permafrost carbon to climate change-Implications for the global carbon cycle: BioScience, v. 58, no. 8, p. 701-714.

Sharma, P.V., 2002 (reprinted), Environmental and engineering geophysics: Cambridge, United Kingdom, Cambridge University Press, 472 p.

Siemon, Bernhard, 2006, Electromagnetic methods-Frequency domain airborne techniques, in Kirsch, R., ed., Groundwater geophysics-A tool for hydrogeology: Berlin, Springer-Verlag, p. 155-170.

Smith, B.D., Irvine, Richard, Blome, C.D., Clark, A.K., and Smith, D.V., 2003, Preliminary results, helicopter electromagnetic and magnetic survey of the Seco Creek area, Medina and Uvalde Counties, Texas: Proceedings for the Symposium on the Application of Geophysics to Environmental and Engineering Problems, $15 \mathrm{p}$.

Smith, B.D., Abraham, J.D., Cannia, J.C., Minsley, B.J., Deszcz-Pan, Maria, and Ball, L.B., 2010, Helicopter electromagnetic and magnetic geophysical survey data, portion of the North Platte and South Platte Natural Resources Districts, western Nebraska, May 2009: U.S. Geological Survey Open-File Report 2010-1259, 33 p.

Smith, B.D., Hodges, Greg, Minsely, B.J., Astley, B.N., Abraham, J.D, Snyder, C.S., 2011, Results from two helicopter electromagnetic test lines to map permafrost, Fort Wainwright, 
Fairbanks, Alaska: 24th Symposium on the Application of Geophysics to Engineering and Environmental Problems, Charleston, S.C., 1 p.

Smith, R.S., and O'Connell, M.D., 2005, Interpolation and gridding of aliased geophysical data using constrained anisotropic diffusion to enhance trends: Geophysics, v. 70, p. V121-V127.

Walvoord, M.A., and Striegl, R.G., 2007, Increased groundwater to stream discharge from permafrost thawing in the Yukon River basin: Potential impacts on lateral export of carbon and nitrogen: Geophysical Research Letters, v. 34, doi:10.1029/2007GL030216.

Webring, Michael, 1981, MINC: A gridding program based on minimum curvature: U.S. Geological Survey Open-File Report 81-1224, 12 p.

Williams, J.R., 1962, Geologic reconnaissance of the Yukon Flats district, Alaska: U.S. Geological Survey Bulletin 1111-H, p. 289-331, 1 sheet, scale 1:500,000, accessed September 2011 at http://www.dggs.dnr.state.ak.us/pubs/id/3617. 


\section{Appendix 1: Fugro Airborne, Ltd., Geophysical Report}

folder.

The contractor's report (Appendix1_FugroReport.pdf) is given in the APPENDIXES

\section{Appendix 2: Calibration Procedure Summary}

The calibration summary (Appendix2_CalibrationSummary.pdf) is given in the APPENDIXES folder.

\section{Appendix 3: Fort Wainwright Poster Presentation}

A poster presenting the results from the Fort Wainwright AEM study area (Appendix3_FtWainwrightResultsPresentation_SmithAndOthers2011.pdf) is given in the APPENDIXES folder. 